\title{
CUATRO PREGUNTAS CON RESPUESTA Y UN APÓLOGO
}

\section{FOUR QUESTIONS TO ANSWER AND AN APOLOGIST}

\section{AUTORES}

José Antonio Martínez Pons: Departamento de Ingeniería Química y Química Analítica. Universidad de Alcalá.

jose.antonio@arrakis.es

\section{CURRÍCULUM VITAE}

Licenciado en Geofísica y Química Física. Profesor del Departamento de Ingeniería Química y Química Analítica. Universidad de Alcalá de Henares (España) y miembro del Ministerio de Educación y Ciencia de España.

\section{RESUMEN}

De las dos actividades que per se debe desarrollar el profesor universitario, en general la menos apreciada es la docencia, preterida siempre o casi siempre por la investigación. Sin embargo esta actividad, a mi pobre saber, es la que da razón de ser a la Universidad. Hasta el título más apreciado "Doctor" viene de "doceo", enseñar, y el último barbarismo que nos ha llegado de allende los mares, el monstruoso "master", en el fondo no es sino la corrupción anglosajona del latino "magister". (Uno sigue preguntándose por qué este complejo de inferioridad de los mediterráneos frente a los bárbaros germánicos, británicos y yanquis, a fin de cuentas cuando aquí se sentaban las bases de la ciencia y la filosofía, allí andaban por la Selva Negra persiguiendo jabalíes y no creo que su mente, la del bárbaro medio, haya 
evolucionado demasiado, salvo cambiar jabalíes por pieles rojas, judíos o hinchas del equipo contrario).

\title{
PALABRAS CLAVE
}

Preguntas - Respuestas - Profesor - Docencia

\begin{abstract}
Of the two activities should be developed per the university professor, generally less appreciated is teaching, always or almost always passed over for research. However, this activity, my poor knowledge, is the rationale given to the University. Even the most cherished title "Doctor" comes from "Twelve", teach, and the last barbarism that has come from overseas, the monstrous "master" in the background is not corruption but the Anglo-Saxon from the Latin "magister". (One still wonders why this inferiority complex of the Mediterranean against Germanic barbarians, Brits and Yanks, after all when here laid the foundations of science and philosophy, there went through the Black Forest and chasing wild boars I think his mind, that of barbaric means, have evolved much, but boars change for Indians, Jews and supporters of the opposing team).
\end{abstract}

\section{KEY WORDS}

Questions - Answers - Teacher - Teaching 


\section{CUATRO PREGUNTAS CON RESPUESTA Y UN APÓLOGO}

Reflexiones sin malicia de un docente veterano (Viejo, para ser claros).

De las dos actividades que per se debe desarrollar el profesor universitario, en general la menos apreciada es la docencia, preterida siempre o casi siempre por la investigación. Sin embargo esta actividad, a mi pobre saber, es la que da razón de ser a la Universidad. Hasta el título más apreciado "Doctor" viene de "doceo", enseñar, y el último barbarismo que nos ha llegado de allende los mares, el monstruoso "master", en el fondo no es sino la corrupción anglosajona del latino "magister". (Uno sigue preguntándose por qué este complejo de inferioridad de los mediterráneos frente a los bárbaros germánicos, británicos y yanquis, a fin de cuentas cuando aquí se sentaban las bases de la ciencia y la filosofía, allí andaban por la Selva Negra persiguiendo jabalíes y no creo que su mente, la del bárbaro medio, haya evolucionado demasiado, salvo cambiar jabalíes por pieles rojas, judíos o hinchas del equipo contrario).

La docencia se define entre nosotros como "carga docente" y muchos la llevan como eso, una carga.

Yo en mi ignorancia llevo mucho tiempo preguntándome al respecto:

¿Qué enseñamos?

¿Cómo enseñamos?

¿A quienes enseñamos y para qué?

¿Cómo evaluamos?

También me pregunto quiénes somos y cómo hemos llegado al profesorado, pero esta pregunta la dejo, de momento, fuera de mis reflexiones, cada cual que se mire en el espejo.

A la primera cuestión quizá sea oportuno responder: "Aquello que creemos que sabemos", pero, ¿realmente es lo que precisa el estudiante?, y me refiero a lo que precisa, no a lo que el propio estudiante, falto de perspectiva, cree que precisa. Antes, al menos había un plan común, sobre el papel, en toda España y las carreras se 
iniciaban con un curso común para cada rama, llámese selectivo, primero o como se quiera, en donde se sentaban unas bases medias mínimas para entrar en los estudios propiamente dichos; y entonces los universitarios procedían de un Bachillerato serio y eficaz, con unas pruebas de selección realistas y no demagógicas. Hoy cada Universidad hace lo que le peta y cada profesor o subprofesor más o menos lo mismo. Al final un estudiante de ingeniería puede acabar la carrera sin haber visto una sola asignatura de química en nivel universitario, un químico ,(el químico que no es físico no es nada en absoluto, Bunsen dixit), con un ligero baño de física que, aunque está en primero suele "aprobar" al final de su ciclo universitario et sic porro. Eso sí, a lo mejor ha cubierto no sé cuantos créditos con el estudio de las costumbres sexuales de los anélidos en climas templados o ha sido capaz de aprender ecuaciones diferenciales antes de estudiar cálculo infinitesimal. (Véase programa de matemáticas de la actual licenciatura en químicas).

A la segunda debo decir que "como buenamente podemos". Aprendemos el oficio a base de batacazos. Nuestras clases son más o menos soporíferas o dinámicas, según nuestras luces, pero en su conjunto, y salvo que ahora tenemos retroproyector, poco se diferencian de las que nos endilgaron a nosotros, $y$, cuidado, líbreme Dios de sugerir siquiera la presencia en las aulas de didácticos y pedagogos, la bondad de cuyas teorías queda patente al tercer bostezo en sus conferencias, que llega más o menos al tercer minuto y tales que, una vez eliminada la verborrea mal traducida del inglés, su ciencia queda en poco más que cero, al menos desde el punto de vista de su aplicación real al alumno real y por el profesor real, no "modelo promedio".

Nuestras clases como digo se limitan, en general, a recitar un manual o una ensalada de manuales, a hacer unos ejercicios y hasta mañana.

Las prácticas, por supuesto, se hacen cuando "el calendario lo permite", con más o menos relación con la materia que se imparte, pero muchas veces sin ninguna relación temporal con la misma. Para colmo, tanto las prácticas como las clases de problemas, si las hay, se encargan al ultimo asociado del departamento, (entiendo por asociado el becario al que se le acaba la beca y algo hay que hacer con él, no lo 
que en teoría debería ser, es decir, alguien que siendo un profesional cualificado dedica una hora a transmitir sus conocimientos en la Universidad, etc, etc...).

¿A quienes? Enseñamos a unos señores muchas veces sin una idea clara de lo que desean, que han dado en nuestra aula por obra y gracia de la nota de corte, o que tienen una idea equivocada de la carrera que quieren estudiar. Estudiantes que llegan a la universidad sin conocimientos ni hábitos de trabajo,(la E.S.O. y el raquítico Bachillerato LOGSE, lejos de remediar el mal lo institucionalizan), y que por desgracia no los adquieren en la Universidad, que a la bajada de base inicial, por obvia no menos grave, reacciona reduciendo años de permanencia y eliminando los cursos comunes.

En realidad su única idea es "aprobar", conseguir un título que les de derecho a ocupar un puesto de trabajo, les importa un rábano formarse. Por supuesto no van al día, preparan las asignaturas muchas veces sólo con base en fotocopias de apuntes.

Copiar es su deber y derecho y en última instancia llorar hasta lograr el aprobado, o el notable o el sobresaliente. Si para ello hay que mentir se miente y si hasta el abuelo debe ir a hablar con el profe, pues va y punto. (Compréndalo, no hemos podido estudiar su asignatura porque hemos tenido ... Así que apruébenos, oído en un despacho universitario).

Que sólo entre un 5 y un $10 \%$ de estudiantes termine la carrera en sus años reglamentados, como dicen los cronistas deportivos, es indicio claro de que algo está muy mal.

¿Cómo evaluamos? Generalmente sobre unos exámenes para los cuales encerramos a los estudiantes en un aula a $40^{\circ} \mathrm{C}$, les pasamos unas preguntas más o menos complicadas, y sobre una base de 3 ó 4 horas emitimos un juicio sobre nuestro, y digo nuestro con todas sus letras, proceso educativo. Me asombra desde mi punto de vista de físico como pueden darse calificaciones con aproximación de centésimas. A mí el punto, según mi instrumento de medida y dejando de lado quimeras estadísticas, me resulta de precisión excesiva. Al final el buen profesor es el que aprueba y el malo el 
que suspende, sin que importe mucho la calidad real de sus enseñanzas o la utilidad de las mismas para la vida profesional del estudiante.

Respecto a la evaluación del método, y dejando de lado la demagógica encuesta que se pasa a los alumnos, nada de nada.

En resumen y poniendo un ejemplo mental, supongamos que mi asignatura es ajedrez, (no descarto que algún día se ponga como optativa para ser ingeniero o troncal en no sé que estudios propios, más formativa que mucho de lo que se enseña, sí es).

El primer día les explicaría que el ajedrez es un juego que se juega en un tablero de 64 escaques, alternativamente blancos y negros. Los estudiantes copiarían como locos, como la mayoría ignoran los que significa escaque, si lo cazan bien y sino, qué más da. Alguno, más audaz, quizá recurriría al "puede repetir", el distraído, dejaría el hueco en blanco y seguiría.

Al día siguiente, por supuesto no se ha repasado la lección del día anterior, ni quien no sabe lo que es un escaque lo habrá mirado en el diccionario, cuando se le cuente que el peón avanza escaque a escaque lo copiará pero se enterará de poco. Como seguirá sin repasar, cuando se llegue al alfil ya no sabrá en dónde se encuentra, si en damas, en ajedrez o parchís, pero copiará apuntes con celo de converso. Sus apuntes, sobre los que preparará el examen, contendrán los errores y lapsus del profesor, los del estudiante y los accidentales de la transmisión.

Las clases de problemas resolverán los clásicos: "negras juegan y dan mate en tres". En las prácticas tendrán un tablero simulado y un guión en el que paso a paso les explicarán lo que deben hacer, con huequecitos en blanco para rellenar con los eventos que vayan sucediendo.

Reivindicarán que se les pongan los exámenes muy espaciados y lo conseguirán de modo que los tres días antes de la prueba pondrán en orden sus apuntes, fotocopiarán del compañero más listo los que le faltan, se pasarán por el departamento a consultar sus "dudas" y el día señalado hale, al examen 
Entonces, además de todo un ceremonial para evitar que copien saquen chuletas y demás historias, (¿por qué el copieteo es característico de España e Italia?), les preguntaremos qué es el rey, cómo se mueve el alfil y, puesto que no hemos llegado a la torre, nuestro ajedrez estará destorreonado. Los problemas serán los típicos, negras juegan y dan mate... pero ojo, no se ha dado la torre, no puede entrar en el examen. Si los problemas no son un calco de los que hemos hecho en clase los mozos y mozas protestarán y nosotros acabaremos poniéndolos así, no sea que en la evaluación nos pongan de malo para arriba.

Al final nosotros pensaremos que hemos enseñado a jugar al ajedrez y ellos, si aprueban, que han aprendido y si suspenden, perdón les suspendemos, ¿para qué está la revisión? Al final cuando logren el cinco se creerán poco menos que Kasparoff pero el primer aficionado les dará el mate del pastor a la primera partida que jueguen.

¿No sería mejor sentarnos cara a cara con el alumno y jugar una partida?, aunque le ganemos, sabremos si sabe o no lo que es el ajedrez y si está en condiciones de algún día ganarnos, lo que sería nuestra gloria como maestros. Creo que así mediremos más su madurez de conocimientos que con una serie de respuestas estereotipadas. (Y quiero olvidar las pruebas de quinielas, ponga $\mathrm{Vd}$. una $\mathrm{X}$ la respuesta correcta, aunque ahora que los yanquis se preguntan sobre su utilidad como medida de conocimientos, aquí las impondremos por ley). 